\title{
Variation for seed physical and hydration properties of chickpea (Cicer arietinum L.) mini core collection and their relevance to conservation and utilization
}

\author{
D. V. S. S. R. Sastry ${ }^{1}$, H. D. Upadhyaya ${ }^{1,2 *}$ and T. R. Srinivas ${ }^{1}$ \\ ${ }^{1}$ International Crops Research Institute for the Semi-Arid Tropics (ICRISAT), Genebank, Patancheru, \\ Telangana, 502 324, India and ${ }^{2}$ King Abdulaziz University, Jeddah, Saudi Arabia
}

Received 3 August 2018; Accepted 11 January 2019

\begin{abstract}
Chickpea (Cicer arietinum L.) is an important grain legume nutritionally balanced for human consumption. The physical properties of chickpea seeds are important for processing and storage as well as for assessing seed quality and the hydration properties related to cooking quality. The chickpea mini core collection ( 211 accessions) and four control cultivars were evaluated for seed morphological (seed colour, shape, dots on seed coat and surface texture); physical (seed moisture content, 100-seed weight, seed coat content, length, width, thickness, geometric mean diameter (GMD), surface area, sphericity, shape aspect, volume, bulk density, true density and porosity); and hydration traits (hydration capacity, hydration index, swelling capacity and swelling index). Highly significant differences were observed for all the seed traits in the mini core collection. Correlation coefficients indicated that accessions with high or more seed weight, GMD, sphericity, seed shape aspect, swelling capacity and swelling index would be useful for utilization in research. The results of this study have refined the seed traits of chickpea and resulted in identifying several desirable accessions in the mini core. Some of these accessions were previously identified as promising sources for important agronomic and nutritional traits and for resistance to biotic and abiotic stresses and will be useful sources to develop high-yielding cultivars with desirable seed physical and hydration quality.
\end{abstract}

Keywords: chickpea, diversity, germplasm, mini core, seed colour, seed shape

\section{Introduction}

Chickpea (Cicer arietinum L.) is an annual grain legume cultivated in over 50 countries across all continents. During 2016, the global chickpea area was about 12.65 million ha, with a production of 12.09 million metric tons (FAOSTAT, 2016). Two main types of chickpea are well recognized - small seeded, with coloured seed coat, angularshaped desi type; and the beige coloured, large seeded, Owl's head shape kabuli type. Another type with pea shape, medium-to-small seed size and cream colour

*Corresponding author. E-mail: h.upadhyaya@cgiar.org recognized as intermediate type. Chickpea seeds are rich in protein, starch, fibre, minerals and vitamins, making it one of the best nutritionally balanced pulses for human consumption (Jukanti et al., 2012) with strong consumer and culinary preferences for utilization. Agbola et al. (2002) described seed quality traits (colour, size and 'dhal' recovery rate) and common uses of chickpea varieties in India. Mehla et al. (2001) reported volume of seed, swelling capacity and hydration capacity as important quality traits. The physical and hydration properties of seeds are important for seed conservation and some traits are important attributes of seed quality, consumer demands and market premiums. In chickpea, seed coat colour has over-riding importance in determining market quality. 
The physical properties of seeds are important in designing equipment and structures for handling, transporting, processing and storage (Nikobin et al., 2009; Wood et al., 2014), for assessing seed quality (Eissa et al., 2010) and for milling and marketing (Ramasamy and Harte, 2009). Mechanical resistance of seeds is a physical property and seeds having greater weight and thickness were less susceptible to mechanical damage. Sastry et al. (2014) have reported relevance of seed physical properties of chickpea germplasm. However, the detailed measurements of the principal dimensions of chickpea seeds and variations in physical and hydration properties have not been investigated in diverse cultivars or germplasm of chickpea. Besides dietary value, the importance of chickpea is also judged by physiochemical and cooking quality traits (Patanè, 2006). Williams et al. (1983) reported a fourfold variation in the time required to cook chickpeas ( 55 to over $200 \mathrm{~min}$ ), and even among kabuli types, a wide variation for cooking time (33-72 min) was observed by Ozer et al. (2010). A large number of chickpea seed samples could be screened using an automated Mattson cooker method, an easy, objective-oriented and more resource-efficient way (Wang and Daun, 2005).

Germplasm collections offer the much needed diversity for important morphoagronomic traits including seed traits (Genebank Database, 2018). The ICRISAT Genebank, Patancheru, India, conserves 20,764 accessions of chickpea from 61 countries. Upadhyaya and Ortiz (2001) developed the chickpea mini core collection (211 accessions) to overcome size-related problems for extensive and economical evaluation and utilization of germplasm. The mini core collection represents both geographical and biological diversity present in cultivated chickpea germplasm. The objective of this study was to investigate the physical and hydration properties of the chickpea mini core collection along with four control cultivars to identify the useful sources of variation for utilization in research to develop cultivars with desirable qualities.

\section{Materials and methods}

The materials for this study consisted of 211 accessions of chickpea mini core collection (Upadhyaya and Ortiz, 2001) and four control cultivars, viz., G 130, L 550, ICCV 2, and ICCV 10. G 130 (ICC 4948) is a desi type, late-maturing cultivar adapted to northern India, L 550 (ICC 4973) is a highyielding, medium-duration kabuli cultivar, tolerant to root knot nematode, but susceptible to Fusarium wilt and Ascochyta blight, and adapted to irrigation conditions in India (Dua et al., 2001). ICCV 2 (ICC 12968) is an earlymaturing and Fusarium wilt-resistant kabuli type, adapted in peninsular India (Kumar et al., 1985). ICCV 10 (ICC 15996) is a short-to-medium duration, high-yielding desi type, resistant to Fusarium wilt and tolerant to dry root rot, drought-tolerant and adapted in the southern and central zones of India (ICRISAT, 1994). The mini core and control cultivars were grown in Vertisols (Kasireddipally series-isohypothermic Type Pellustert) (El-Swaify et al., 1985) during 2016-2017 post rainy season (OctoberApril) at ICRISAT, Patancheru, India. Each accession was planted in a plot of two rows of $4 \mathrm{~m}$ length, with a row-to-row spacing of $60 \mathrm{~cm}$ and plant-to-plant spacing of $10 \mathrm{~cm}$. Freshly harvested seed samples were handthreshed and cleaned samples were stored (two replicates) under short-term storage conditions $\left(20^{\circ} \mathrm{C}\right.$ and $\left.40 \% \mathrm{RH}\right)$ for 2 weeks to attain equilibrium moisture content (emc). Observations were recorded on 22 important seed traits including morphological traits - seed colour, shape, dots on seed coat and surface texture; seed moisture content, 100-seed weight, seed coat content; and principal dimensions of seed size such as length, width and thickness, geometric mean diameter (GMD), surface area, sphericity/roundness index, shape aspect, volume, bulk density, true density, porosity, hydration capacity, hydration index, swelling capacity and swelling index as described below:

\section{Seed colour, shape, dots on seed coat and surface texture}

Visual observations on seed colour, shape, dots on seed coat and surface texture were recorded on clean bulk sample of $200 \mathrm{~g}$ under natural light as naked eye observation using Royal Horticultural Society colour chart (codes) following the Descriptors for Chickpea (IBPGR, ICRISAT, and ICARDA, 1993).

\section{Seed moisture content}

The moisture content of equilibrated seed samples under controlled environment (emc) was estimated on wet weight basis (w. b.) following oven-dry method (ISTA, 1993).

\section{Hundred-seed weight}

The 100-seed weight of the chickpea samples was determined on randomly selected 100 seeds and weighing them using a sensitive balance and weight was recorded in grams.

\section{Seed coat content}

An accurately weighed sample of 10 seeds in each accession was soaked in distilled water for $16 \mathrm{~h}$ at room temperature $\left(25^{\circ} \mathrm{C}\right)$. After the water was drained, the soaked seeds were dried on blotting paper and the seed coat was 
completely removed with tweezers. The seed coats collected were dried in an oven at $60^{\circ} \mathrm{C}$ for $24 \mathrm{~h}$, followed by cooling in a desiccator (Tizazu and Emire, 2010). The seed coats were weighed and the per cent seed coat content to seed weight was calculated.

\section{Seed size}

Seed size was measured in millimetres on principal dimensions such as length, width and thickness. Ten randomly selected seeds from each accession were used to measure length, width and thickness in millimetres, using digital caliper and mean values were determined.

\section{Seed GMD}

The three mutually perpendicular diametrical dimensions of length, width and thicknesses of seed of chickpea were determined and used for calculating the GMD in millimetres following Sreenarayanaa et al. (1988).

\section{Seed surface area, sphericity and shape aspect}

Sphericity is the state or form of being spherical. It is the ratio of the surface area of a given object to the surface area of a sphere with the same volume. The sphericity and shape aspect of chickpea seeds were determined as percentages using the procedures suggested by Mohsenin (1986) and Omobuwajo et al. (1999), respectively.

\section{Seed volume, bulk density, true density and porosity}

Seed physical parameters such as volume, bulk density, true density and porosity are dependent on morphological seed traits and the moisture content of seeds. Hence these parameters were estimated on seed samples at equilibrium moisture contents. For determining the bulk density, true density and the porosity of a seed sample size of $100 \mathrm{~g}$ was used. Bulk density of the seed was calculated by dividing the weight of each sample on its volume (cc), measured by using a graduated cylinder (Eissa et al., 2010). True density and volume were determined by toluene solution displacement method (Mohsenin, 1986). Bulk density and true density were expressed as $\mathrm{g} / \mathrm{cc}$ at given seed moisture conditions. The porosity was determined as the percentage of densities of bulk seeds (Jha, 1999).

\section{Seed hydration and swelling}

The seed hydration capacity (g/seed), hydration index, swelling capacity $(\mathrm{ml} / \mathrm{seed})$ and swelling index of the chickpea mini core accessions were estimated following the procedure adopted by Khattak et al. (2006). Two random samples of 100 seeds from each accession were weighed, number of seeds counted and the values converted to gram per seed. Seed volume was determined by transferring 100 seeds into a $100 \mathrm{ml}$ measuring cylinder, and $50 \mathrm{ml}$ of distilled water were added. The gain in volume divided by 100 was recorded as the seed volume. Hydration capacity was recorded as gain in weight after overnight soaking in distilled water. Hydration index was calculated as hydration capacity divided by original seed weight. The swelling capacity was determined as gain in volume after overnight soaking in water, and swelling index was calculated as swelling capacity divided by original seed volume.

The Principal Component Analysis (PCA) was performed to determine the relative importance of different traits in capturing the variation, and hierarchical clustering was done using scores of the first three PCs to categorize accessions, using the software Genstat 17 Edition.

Data were analysed following completely randomized design using Genstat 14th Edition. Correlation coefficients between different traits were calculated using mean values to determine association between different traits.

\section{Results}

Based on the visual seed colour observations, the $211 \mathrm{mini}$ core accessions were classified into 16 seed colours. Yellow brown (48), beige (45), brown (36), black (21) and yellow (16) were the major seed colours followed by brownish beige (12), light brown (10) and dark brown (9). Dots on seed coat were present in 119 and absent in 92 accessions. Seed shapes were represented by angular (158), Owl's head (44) and pea (9) accessions. Seed surface texture was rough for 159, smooth for 48 and tuberculate for four accessions. On the basis of seed morphological traits, the mini core represented 158 desi type, 44 kabuli type and nine intermediate type (online Supplementary Fig. S1).

Performance of mini core accessions and four control cultivars for seed physical and hydration parameters is presented in Tables 1-3 and online Supplementary Table S1. Considering the range of variation for seed traits, the mini core accessions were grouped in to four or five classes (Table 1). Highly significant differences $(P<0.01)$ among the accessions were observed for the 18 traits related to seed physical, hydration and quality (Table 2). Means and other statistical parameters are presented in Table 2 and online Supplementary Table S1. Correlation coefficients between different traits are given in Table 3. 
Table 1. Frequency distribution for seed physical and hydration properties of chickpea mini core accessions

Seed moisture
$\quad \leq 11.0$
$11.1-11.5$
$11.6-12.0$
$12.1-12.5$
$>12.5$

Hundred-seed weight (g)

$$
\leq 10.0
$$

$10.1-15.0$

$15.1-20.0$

$20.1-25.0$

$>25.0$

Seed coat content $(\%)$

$$
\leq 5.0
$$

$5.1-10.0$

$10.1-15.0$

$>15.0$

Length $(\mathrm{mm})$

$$
\leq 7.0
$$

$7.1-8.0$

8.1-9.0

$>9.0$

Width $(\mathrm{mm})$

$\leq 5.0$

$5.1-6.0$

$6.1-7.0$

$>7.0$

Thickness $(\mathrm{mm})$

$$
\leq 5.0
$$

$5.1-6.0$

$6.1-7.0$

$>7.0$

Volume $\left(\mathrm{mm}^{3}\right)$

$$
\leq 200
$$

201-300

301-400

$>400$

$\mathrm{GMD}(\mathrm{mm})$

$\leq 6.0$

$6.1-7.0$

7.1-8.0

$>8.0$

Surface area $\left(\mathrm{mm}^{2}\right)$

$\leq 100$

101-150

151-200

$>200$

51

62

90

40

78

31

21

106

68

32

5

46

124
Table 1. (Cont.)

Sphericity (\%)

$$
\leq 75.0
$$

1

$75.1-80.0$

104

$80.1-85.0$

74

$85.1-90.0$

$>90.0$

31

1

Seed shape aspect (\%)

$\leq 70.0$

55

70.1-75.0

108

32

16

$>80.0$

13

$\leq 0.65$

$0.66-0.70$

$0.71-0.75$

97

98

$>0.75$

3

True density (g/cc)

$$
\leq 1.20
$$

1.21-1.25

25

1.26-1.30

115

1.31-1.35

$>1.35$

64

1

Porosity (\%)

$$
\leq 50.0
$$

6

50.1-55.0

122

55.1-60.0

80

$>60.0$

3

Hydration capacity (g/seed)

$$
\leq 0.10
$$

0.11-0.20

151

0.21-0.30

35

$>0.30$

19

Hydration index

$$
\leq 1.10
$$

1.11-1.20

140

1.21-1.30

38

$>1.30$

2

Swelling capacity $(\mathrm{ml} / \mathrm{seed})$ $\leq 0.10$ 20

0.11-0.20

146

$0.21-0.30$

33

$>0.30$

12

Swelling index

$$
\leq 1.00
$$

1.01-1.05

63

1.06-1.20

82

$>1.20$ 
Table 2. Range, means and statistical parameters of seed physical and hydration properties of chickpea mini core accessions along with control cultivars

\begin{tabular}{|c|c|c|c|c|c|c|c|c|c|c|c|}
\hline \multirow[b]{2}{*}{ Observation } & \multirow[b]{2}{*}{ Range } & \multirow{2}{*}{$\begin{array}{l}F \text { test } \\
<0.01\end{array}$} & \multirow{2}{*}{$\begin{array}{l}\text { CV } \\
(\%)\end{array}$} & \multirow{2}{*}{$\begin{array}{l}\text { Overall } \\
\text { Mean }\end{array}$} & \multirow{2}{*}{$\begin{array}{l}\text { Desi } \\
\text { Mean }\end{array}$} & \multirow{2}{*}{$\begin{array}{l}\text { Kabuli } \\
\text { Mean }\end{array}$} & \multirow{2}{*}{$\begin{array}{c}\text { Intermediate } \\
\text { Mean }\end{array}$} & \multicolumn{4}{|c|}{ Controls } \\
\hline & & & & & & & & G 130 & L 550 & ICCV 2 & ICCV 10 \\
\hline Moisture content (\%) & $10.1-12.8$ & $* *$ & 0.51 & 11.7 & 11.7 & 11.8 & 12.0 & 12.1 & 12.2 & 12.1 & 12.2 \\
\hline Hundred-seed weight (g) & $8.1-36.7$ & $* *$ & 5.54 & 15.6 & 13.2 & 24.1 & 16.4 & 10.0 & 19.3 & 22.6 & 17.1 \\
\hline Seed coat content $(\%)$ & $4.1-19.6$ & $* *$ & 6.46 & 13.1 & 15.4 & 5.2 & 11.4 & 15.8 & 4.9 & 7.2 & 12.2 \\
\hline Length $(\mathrm{mm})$ & $6.4-9.6$ & $* *$ & 1.96 & 7.7 & 7.5 & 8.4 & 7.8 & 7.2 & 8.0 & 8.3 & 7.4 \\
\hline Width (mm) & $4.5-7.6$ & $* *$ & 3.21 & 5.6 & 5.4 & 6.6 & 5.8 & 5.0 & 6.4 & 6.8 & 5.8 \\
\hline Thickness (mm) & $4.5-7.9$ & $* *$ & 3.09 & 5.6 & 5.3 & 6.8 & 6.0 & 4.8 & 6.4 & 6.8 & 5.8 \\
\hline Volume $\left(\mathrm{mm}^{3}\right)$ & $131-548$ & $* *$ & 7.00 & 256 & 220 & 384 & 270 & 172 & 328 & 390 & 255 \\
\hline Geometric mean diameter $(\mathrm{mm})$ & $5.1-8.2$ & $* *$ & 2.27 & 6.3 & 6.0 & 7.2 & 6.5 & 5.6 & 6.9 & 7.3 & 6.3 \\
\hline Surface area $\left(\mathrm{mm}^{2}\right)$ & $81-221$ & $* *$ & 4.58 & 125 & 113 & 165 & 131 & 97 & 150 & 168 & 126 \\
\hline Sphericity (\%) & $73.4-90.4$ & $* *$ & 1.69 & 81.0 & 79.5 & 85.7 & 84.5 & 76.9 & 86.1 & 87.8 & 85.3 \\
\hline Seed shape aspect (\%) & $65.4-84.2$ & $* *$ & 2.93 & 72.9 & 71.2 & 78.2 & 76.3 & 68.5 & 79.4 & 82.1 & 77.7 \\
\hline Bulk density (g/cc) & $0.578-0.791$ & $* *$ & 2.06 & 0.700 & 0.702 & 0.691 & 0.707 & 0.725 & 0.724 & 0.714 & 0.723 \\
\hline True density (g/cc) & $1.104-1.372$ & $* *$ & 2.27 & 1.286 & 1.293 & 1.261 & 1.293 & 1.269 & 1.192 & 1.299 & 1.329 \\
\hline Porosity (\%) & $45.2-64.0$ & $* *$ & 2.35 & 54.4 & 54.3 & 54.9 & 54.9 & 57.1 & 60.7 & 55.0 & 54.4 \\
\hline Hydration capacity (g/seed) & $0.096-0.485$ & $* *$ & 3.94 & 0.182 & 0.153 & 0.285 & 0.190 & 0.117 & 0.213 & 0.179 & 0.199 \\
\hline Hydration index & $1.011-1.309$ & $* *$ & 1.98 & 1.161 & 1.158 & 1.180 & 1.127 & 1.174 & 1.173 & 1.227 & 1.34 \\
\hline Swelling capacity (ml/seed) & $0.082-0.463$ & $* *$ & 5.08 & 0.163 & 0.137 & 0.255 & 0.173 & 0.114 & 0.213 & 0.148 & 0.191 \\
\hline Swelling index & $0.879-1.577$ & $* *$ & 3.59 & 1.043 & 1.039 & 1.063 & 1.025 & 1.147 & 1.172 & 1.087 & 1.083 \\
\hline No. of observations & & & & 211 & 158 & 44 & 9 & & & & \\
\hline
\end{tabular}

**Significant differences at $P=0.01$. 
Table 3. Correlations among physical and hydration properties of the chickpea mini core accessions

\begin{tabular}{|c|c|c|c|c|c|c|c|c|c|}
\hline Trait & EMC & SWT & SCC & SL & SW & ST & SV & GMD & SA \\
\hline SWT & 0.032 & & & & & & & & \\
\hline SCC & -0.106 & -0.774 & & & & & & & \\
\hline SL & -0.005 & 0.901 & -0.598 & & & & & & \\
\hline SW & 0.059 & 0.959 & -0.762 & 0.892 & & & & & \\
\hline ST & 0.074 & 0.961 & -0.808 & 0.873 & 0.965 & & & & \\
\hline SV & 0.040 & 0.982 & -0.757 & 0.924 & 0.984 & 0.975 & & & \\
\hline GMD & 0.050 & 0.971 & -0.758 & 0.938 & 0.986 & 0.983 & 0.993 & & \\
\hline SA & 0.045 & 0.979 & -0.759 & 0.933 & 0.987 & 0.981 & 0.999 & 0.999 & \\
\hline SSp & 0.147 & 0.674 & -0.755 & 0.388 & 0.740 & 0.774 & 0.683 & 0.683 & 0.685 \\
\hline SSA & 0.135 & 0.620 & -0.678 & 0.339 & 0.727 & 0.686 & 0.638 & 0.630 & 0.635 \\
\hline SBD & 0.015 & -0.332 & 0.049 & -0.405 & -0.341 & -0.329 & -0.356 & -0.363 & -0.360 \\
\hline STD & -0.032 & -0.284 & 0.301 & -0.245 & -0.275 & -0.278 & -0.281 & -0.275 & -0.278 \\
\hline SP & 0.040 & -0.086 & -0.179 & -0.183 & -0.102 & -0.089 & -0.111 & -0.122 & -0.116 \\
\hline SHyC & 0.025 & 0.983 & -0.767 & 0.882 & 0.938 & 0.942 & 0.966 & 0.951 & 0.960 \\
\hline SHyl & 0.047 & -0.061 & -0.079 & -0.086 & -0.075 & -0.061 & -0.052 & -0.075 & -0.063 \\
\hline SwC & 0.035 & 0.970 & -0.787 & 0.857 & 0.926 & 0.932 & 0.950 & 0.936 & 0.945 \\
\hline Swl & 0.068 & -0.137 & -0.122 & -0.218 & -0.147 & -0.131 & -0.147 & -0.164 & -0.156 \\
\hline Trait & SSp & SSA & SBD & STD & SP & SHyC & SHyl & SwC & \\
\hline SSA & 0.958 & & & & & & & & \\
\hline SBD & -0.117 & -0.100 & & & & & & & \\
\hline STD & -0.211 & -0.196 & 0.267 & & & & & & \\
\hline SP & 0.055 & 0.060 & 0.714 & -0.485 & & & & & \\
\hline SHyC & 0.657 & 0.603 & -0.337 & -0.314 & -0.068 & & & & \\
\hline SHyl & -0.032 & -0.042 & 0.067 & -0.095 & 0.129 & 0.048 & & & \\
\hline SwC & 0.669 & 0.615 & -0.256 & -0.386 & 0.060 & 0.986 & 0.017 & & \\
\hline Swl & 0.014 & 0.015 & 0.477 & -0.363 & 0.695 & -0.084 & 0.441 & 0.042 & \\
\hline
\end{tabular}

EMC, equilibrium moisture content; SWT, 100-seed weight; SCC, seed coat content; SL, seed length; SW, seed width; ST, seed thickness; SV, seed volume; GMD, geometric mean diameter; SA, seed surface area; SSp, seed sphericity; SSA, seed shape aspect; SBD, seed bulk density; STD, seed true density; SP, seed porosity; SHyC, seed hydration capacity; SHyl, seed hydration index; SwC, seed swelling capacity; Swl, seed swelling index.

Significance levels : $<0.05 \%=0.133$ and $<0.01 \%=0.175$.

\section{Seed moisture content}

Seed moisture content $(\mathrm{emc})$ is an important measure of seed quality influencing the physical parameters, seed handling procedures and storage behaviour of the seeds in genebanks. The emc of the accessions ranged from 10.1 to $12.8 \%$ with a mean of $11.7 \%$ (Table 2 ). The mini core accessions were classified in to five seed moisture classes (Table 1). The lowest emc was observed in ICC 15406, a kabuli type with a 100-seed weight $28.6 \mathrm{~g}$ and highest emc in ICC 11378, a desi type with a 100-seed weight $12.3 \mathrm{~g}$. The mean moisture contents of the desi, kabuli and intermediate types were $11.7,11.8$ and $12.0 \%$, respectively. The emc of the four control cultivars was similar (12.1-12.2\%), but were significantly higher than that of desi and kabuli types.

\section{Seed weight}

The 100-seed weight of the mini core accessions ranged from 8.1 to $36.7 \mathrm{~g}$ with a mean of $15.6 \mathrm{~g}$ (Table 2). Based on the 100-seed weight, the mini core accessions were classified in to five seed weight classes (Table 1). The small seed weight $(<10 \mathrm{~g})$ was represented by 27 accessions and the large seed weight $(>30 \mathrm{~g}$ ) by nine accessions. ICC 13124, a desi type, had the smallest and ICC 15518, a kabuli type, the largest for 100-seed weight. Accessions 
with a 100-seed weight range of 8.0-9.3 g were ICCs 3230, 3761, 4607, 4814, 5845, 7184, 12299, 13124, 13892 and 14077; and the large-seeded accessions with a 100-seed weight between 29.7 and $36.6 \mathrm{~g}$ were ICCs 8151, 8261, 9137, 12328, 12866, 14199, 15333, 15518, 15697 and 16796. The mean 100-seed weights of the desi, kabuli and intermediate types were 13.2, 24.1 and $16.4 \mathrm{~g}$, respectively. Significant differences were also observed between the 100-seed weights of the control cultivars. G 130 had the lowest 100-seed weight (10.0 g) and ICCV 2 had the highest 100-seed weight $(22.6 \mathrm{~g})$.

\section{Seed coat content}

Significant differences were observed in the seed coat content of the mini core accessions which ranged from 4.1 to $19.6 \%$ with an overall mean of $13.1 \%$ (Table 2). A seed coat content of $<5 \%$ was observed in 21 mini core accessions and $>15 \%$ in 91 accessions (Table 1). ICC 7272 , a kabuli type with a 100 -seed weight of $28.1 \mathrm{~g}$, had the lowest seed coat content and ICC 13219, a desi type with a 100-seed weight of $12.3 \mathrm{~g}$, had the highest seed coat content. Overall the three groups, desi, kabuli and intermediate types, had vast differences in the mean seed coat contents. Kabuli types had lowest seed coat content (5.2\%) and the desi types had almost three times (15.4\%) and intermediate types (11.4\%) more than two times seed coat content than the kabuli types. Ten accessions identified with lowest seed coat content were all kabuli type (ICCs 4841, 7255, 7272, 7308, 8261, 10755, 10885, 11764, 12328 and 14199) and 10 accessions with highest seed coat content were all desi type (ICCs 1083, 5639, 5845, 6811, 7441, 11498, 13219, 15612, 15868 and 16261). The control cultivars also differed significantly for seed coat content. L 550 (kabuli type) has the lowest seed coat content (4.9\%), and G 130 (desi type) has the highest seed coat content (15.8\%).

\section{Seed physical dimensions}

The mini core accessions differed significantly for all the seed physical dimensions (Table 2). Seed length of the mini core accessions ranged from 6.4 to $9.6 \mathrm{~mm}$ with a mean of $7.7 \mathrm{~mm}$. Eleven accessions had a seed length $>9.0 \mathrm{~mm}$. Similarly, the seed width ranged from 4.5 to $7.6 \mathrm{~mm}$ and 16 accessions had a seed width $>7.0 \mathrm{~mm}$. Seed thickness in mini core ranged from 4.5 to $7.9 \mathrm{~mm}$ with a mean of $5.6 \mathrm{~mm}$. Nineteen accessions had a seed thickness $>7.0 \mathrm{~mm}$. The seed volume of mini core accessions showed a fourfold range from 131 to $548 \mathrm{~mm}^{3}$ with a mean of $256 \mathrm{~mm}^{3}$. Twenty-one accessions had a seed volume $>400 \mathrm{~mm}^{3}$. The mean GMD of mini core was $6.3 \mathrm{~mm}$ and five accessions had $>8.0 \mathrm{~mm}$ GMD. The mean GMD and seed volume of the desi, kabuli and intermediate types were 6.0, 7.2 and $6.5 \mathrm{~mm} ; 220,384$ and 270 $\mathrm{mm}^{3}$, respectively. The control cultivars differed significantly for seed size dimensions. G 130 was the smallest in size and ICCV 2 was the largest.

Based on the seed size dimensions, the mini core accessions were classified into four classes for GMD, length, width, thickness and volume (Table 1). Seed surface area of the accessions ranged from 81 to $211 \mathrm{~mm}^{2}$ with a mean of $125 \mathrm{~mm}^{2}$ (Table 2) and the accessions were classified in to four surface area classes (Table 1). Six mini core accessions had a surface area $>200 \mathrm{~mm}^{2}$. Based on seed GMD and surface area measurements, ICCs 3230, 5845, 7184, 12299 and 13124 were classified as the small-seeded (all desi type) and ICCs 9137, 12328, 15518, 15697 and 16796 as large-seeded (all kabuli type) in the mini core collection. Ten accessions identified with largest seed volume, GMD and surface area in the mini core collection (ICCs 8151, 8261, 9137, 10885, 12328, 14199, 15333, 15518, 15697 and 16796) were all kabuli type.

\section{Seed sphericity and shape}

Seed sphericity and shape aspect are related traits and are useful in defining the roundness of chickpea seeds. Observations on sphericity of seeds showed significant differences among the mini core accessions (Table 2). The sphericity recorded at emc ranged from 73.4 to $90.4 \%$ with a mean of $81.0 \%$. The lowest sphericity was observed in ICC 1083, a desi type, and the highest in ICC 7323, an intermediate type. One hundred and five mini core accessions had $<80 \%$ and 32 accessions $>85 \%$ seed sphericity. The kabuli types had highest mean sphericity (85.7\%) followed by intermediate types (84.5\%) and desi types (79.5\%).

The seed shape aspect of the mini core collection ranged from 65.4 to $84.2 \%$ with a mean of $72.9 \%$ (Table 2). Fifty-five accessions had $<70 \%$ and 16 accessions had $>80 \%$ seed shape aspect. The mini core accessions were classified in to five classes for sphericity and four classes for seed shape aspect (Table 1). The seed shape aspect was poor in ICC 1194, a desi type, and the best in ICC 7323, an intermediate type. Based on the observations, ICCs 708, 1083 and 1194 were found poor and ICCs 7323, 9137, 13187 and 15518 as best for seed sphericity and shape aspect. The kabuli types had the best (78.2\%), followed by intermediate (76.3\%) and desi types (71.2\%). Ten accessions identified with highest sphericity were ICCs 6363, 7308, 7323, 8151, 8261, 9137, 11764, 13187, 13283 and 15518 and nine of these represent highest seed shape aspect. All these accessions were kabuli type except ICC 7323 , an intermediate type. The control cultivars also differed significantly for seed sphericity and seed shape aspect. Seed 
sphericity and shape aspect were highest in ICCV 2 and lowest in G 130.

\section{Seed density and porosity}

The 211 mini core accessions showed significant differences for the bulk density, true density and porosity of seeds. The bulk density ranged from 0.578 to $0.791 \mathrm{~g} / \mathrm{cc}$ with a mean of $0.700 \mathrm{~g} / \mathrm{cc}$ (Table 2). The lowest bulk density was observed in ICC 16903, a desi type chickpea with a 100 -seed weight $14.4 \mathrm{~g}$ and a seed coat content $17.1 \%$. Five accessions, ICCs 8151, 13219, 14669, 15612 and 15612, had a seed bulk density $\geq 0.750 \mathrm{~g} / \mathrm{cc}$. The seed true density ranged from 1.104 to $1.372 \mathrm{~g} / \mathrm{cc}$ with a mean of $1.286 \mathrm{~g} / \mathrm{cc}$. The mean bulk density and true density of the desi, kabuli and intermediate types were $0.702,0.691$ and $0.707 \mathrm{~g} / \mathrm{cc}$; and $1.293,1.261$ and $1.293 \mathrm{~g} / \mathrm{cc}$, respectively. Ten accessions identified with highest true density were ICCs 637 , 708, 791, 1052, 1915, 3218, 8350, 12492, 12928 and 15606. This includes eight desi, one kabuli and one intermediate type. Two of these accessions, ICC 708 (desi) and ICC 12492 (kabuli) with 100-seed weights 13.8 and $16.5 \mathrm{~g}$ respectively, also had high bulk density. The seed porosity is a relative value based on the two densities and ranged from 45.2 to $64.0 \%$ with a mean of $54.4 \%$ in the mini core collection. Three accessions (ICCs 8261, 9137 and 10341) had a porosity $>60 \%$. The seed bulk density and porosity was highest in ICC 10341, a kabuli type with a 100 -seed weight $19.2 \mathrm{~g}$ and a seed coat content $6.0 \%$. The lowest porosity was in ICC 16903 , a desi type with a 100 -seed weight $14.4 \mathrm{~g}$ and a seed coat content $17.1 \%$. Based on the observations, the mini core accessions were classified into four classes each for bulk density and porosity and five classes for true density (Table 1). Mean seed porosities of the desi, kabuli and intermediate types were $54.3,54.9$ and $54.9 \%$, respectively. The control cultivars also differed significantly for seed bulk density and seed true density. G 130 and ICCV 10 (both desi types) had the highest bulk density and true density among the control cultivars.

\section{Seed hydration and swelling}

Significant differences were observed among the mini core accessions for both seed hydration capacity and hydration index (Table 2). Seed hydration capacity in the mini core ranged from 0.096 to $0.485 \mathrm{~g} / \mathrm{seed}$ with a mean of 0.182 $\mathrm{g} / \mathrm{seed}$. Seed hydration index of accessions ranged from 1.011 to 1.309 with a mean of 1.161 . Seed swelling capacity ranged from 0.082 to $0.463 \mathrm{ml} / \mathrm{seed}$ with a mean of 0.163 $\mathrm{ml} / \mathrm{seed}$. Seed swelling index of accessions ranged from 0.879 to 1.577 with a mean of 1.043 . The seed hydration capacity and swelling capacity was highest in ICC 9137, a kabuli type with 100-seed weight $35.5 \mathrm{~g}$ and a seed coat content $4.7 \%$; and lowest in ICC 13124 , a desi type with 100 -seed weight $8.0 \mathrm{~g}$ and a seed coat content $17.5 \%$. The seed hydration index was highest in ICC 13077, a kabuli type with a 100-seed weight $19.0 \mathrm{~g}$ and a seed coat content $5.8 \%$, and was lowest in ICC 5879, a desi type with a 100-seed weight $14.8 \mathrm{~g}$ and a seed coat content $13.3 \%$. The mean hydration capacity and hydration index of the desi, kabuli and intermediate types were $0.153 \mathrm{~g} / \mathrm{seed}$ and $1.158 ; 0.285 \mathrm{~g} /$ seed and 1.180 ; and $0.190 \mathrm{~g} / \mathrm{seed}$ and 1.127, respectively. Ten accessions (ICCs 8151, 9137, 12328, 13283, 14199, 15333, 15406, 15518, 15697 and 16796) that were identified with highest hydration capacity were kabuli type and nine among these accessions had highest swelling capacity also. The mean swelling capacity and swelling index of the desi, kabuli and intermediate types were $0.137 \mathrm{ml} /$ seed and $1.039 ; 0.255 \mathrm{ml} /$ seed and $1.063 ; 0.173 \mathrm{ml} / \mathrm{seed}$ and 1.025 , respectively. Five accessions (ICCs 3948, 12654, 12726, 14051 and 14077) representing desi type and five accessions (ICCs 9137, 13077, 13461, 13816 and 15802) representing kabuli type were among the 10 accessions which had highest hydration index. Highest swelling index was recorded in ICCs 3761, 6537, 8195 and 3524 (desi type), ICCs 8261, 9137, 11879, 13077 and 13764 (kabuli type) and ICC 13041, an intermediate type chickpea. Based on the observations, the mini core accessions were classified in to four classes for seed hydration capacity, hydration index, swelling capacity and swelling index (Table 1). The four control cultivars also had significantly different seed hydration and swelling characteristics. The seed hydration capacity, swelling capacity and swelling index were highest in L 550 (kabuli type) and ICCV 10 (desi type). The porosity was highest in L 550 (kabuli type) and hydration index was highest in ICCV 10 (desi type) among the cultivars.

\section{Correlations among seed traits}

Correlation coefficients among seed physical and hydration traits are presented in Table 3. Seed moisture content was poorly correlated with all seed traits except seed sphericity and shape aspect. Since, all the seed samples were dried to a lower emc, the moisture range across seed types was also narrow. Correlations among 100-seed weight and seed coat content, bulk density, true density and seed swelling index were negative and highly significant. However, significant positive correlations were observed with seed physical dimensions, sphericity, shape aspect, porosity, hydration capacity and swelling capacity. Seed coat content was negatively correlated with seed physical dimensions, sphericity, seed shape aspect, hydration capacity and swelling capacity, however, positively associated with seed true density. All seed physical dimensions were positively 
correlated contributing to larger seed volume and surface, sphericity and seed shape aspect in the mini core accessions. However, seed dimensions were negatively associated with seed densities and porosity. Both seed densities were positively correlated; however, seed porosity was positively associated with bulk density and negatively with true density. Seed hydration capacity was positively associated with hydration index and swelling capacity.

PCA indicated that the first PC (PC 1) explained 59.3\% of variation followed by PC 2 (14.8\%) and PC 3 (7.0\%) and the three PCs together explained $81.05 \%$ variation. The important traits involved in the PC 1 were seed weight, GMD, hydration capacity, seed coat content, seed length, thickness, seed volume, seed width, seed sphericity, seed surface area and seed swelling capacity. For PC 2, the important traits were seed bulk density, seed porosity and seed swelling index, and for PC 3, only the seed true density. Of the 15 traits involved in the first three PCs, only two traits, seed coat content in PC 1 and seed true density in the PC 3, contributed negatively.

A hierarchical cluster analysis conducted using scores of the first three PCs resulted in to three clusters (figure not included). Cluster 1 comprised of 26 accessions largely represented by kabuli types except one desi accession; cluster 2 comprised of 57 accessions represented by all three types, desi (30), kabuli (19) and intermediate (8) types; cluster 3 comprised of 128 accessions all desi type except one intermediate type accession.

The accessions in cluster 1 had high mean values for seven traits (100-seed weight, seed volume, surface area, sphericity, seed shape aspect, hydration capacity, swelling capacity) while those in cluster 2 for four traits (seed moisture content, seed bulk density, porosity, swelling index) and in cluster 3 for three traits (seed coat content, seed true density, seed hydration index) (data not given).

\section{Discussion}

Chickpea, like many other legumes, has a narrow genetic base due to bottlenecks associated with its domestication (Abbo et al., 2003). The chickpea mini core (Upadhyaya and Ortiz, 2001) selected from the core collection (Upadhyaya et al., 2001) represents diversity of entire collection including the three different seed types described for chickpea. The mini core accessions differed significantly for all the 18 seed physical and hydration traits, indicating that there was adequate diversity in the mini core collection for these traits. In the present study, the mean moisture contents of the desi, kabuli and intermediate types were 11.7, 11.8 and $12.0 \%$, respectively. The range of variation in the emc could be attributed to large diversity in seed size and seed coat thickness for exchanging moisture with surrounding environment (Sastry et al., 2014). However, a large number of accessions (161) were within a narrow range of emc (11.5-12.5\%). Seed emc contributed positively to seed sphericity and seed shape aspect. The seed shape directly affects the seed appearance and uniformity of chickpea which are important quality indicators for importers and consumers.

The chickpea mini core represents desi (158), kabuli (44) and intermediate (9) types. Large diversity was observed for seed morphological traits, especially the seed coat colour and shape observed in the mini core collection. In chickpea, seed coat colour has over-riding importance in determining seed quality. Seed coat and coloured seed are major sources for phytochemicals and accessions with higher seed coat content associated with dark seed coat colours offer abundant opportunity to discover variations in health-promoting phytochemicals. Physical measurements on seed geometric traits and further classification of accessions in to different classes significantly contribute to visual observations on seed size and shape.

The mini core collection represented large variation for 100-seed weight $(8.1-36.7 \mathrm{~g})$. Overall the kabuli types had on average greater mean 100-seed weight (24.1 g) than the desi types $(13.2 \mathrm{~g})$ and intermediate types (16.4 g). Nine mini core accessions had $>30 \mathrm{~g}$ 100-seed weight, whereas 23 accessions had a 100-seed weight of $<10$ g. Seed weight was negatively correlated to seed coat content, seed densities and seed swelling index; and positively correlated to all seed dimensional traits and seed hydration and swelling capacities. Seed weight and volume are important attributes determining the consumer preference and cooking quality of chickpea cultivars. In the present study, the 100-seed weight was higher in 32 accessions than the best control cultivar ICCV $2(22.6 \mathrm{~g})$ and 10 accessions with highest 100-seed weight (29.7-36.6 g) represent kabuli types. Consumers prefer large-seeded types for whole seed consumption, confectionary products, salads and savoury meals (Regan et al., 2006). Seed size is an important trait of kabuli type chickpea and cultivars with 100 -seed weight of $>40 \mathrm{~g}$ garner higher market price as they are preferred by consumers (Gowda et al., 2011).

The mini core accessions showed large variation for seed coat content (4.1-19.6\%). Overall, kabuli types had lowest seed coat content $(5.2 \%)$ and the desi types had almost three times (15.4\%) and intermediate types (11.4\%) more than two times seed coat content than the kabuli types. Sastry et al. (2014) also reported fourfold variation in the seed coat contents among 50 chickpea accessions. Singh et al. (1980) also reported higher seed coat contents in desi types (14.2\%) than in kabuli types (4.9\%). Seed coats of desi types were 2.72 times thicker than kabuli types with normal testa and 3-25 times thicker than kabuli types with cracked testa in the studies of Yadav and Sharma, 2000. 
Wood et al. (2011) reported the differences in the processing of desi and kabuli types on the basis of morphology and composition of seed coats. Physical characteristics of chickpea seeds such as grain size, weight and hull content are important for milling and marketing (Ramasamy and Harte, 2009) and difficult milling in chickpea is associated with seed coat traits and a more flexible seed coat resists cracking and decortication. There is growing evidence of seed coat characteristics to specific seed problems like susceptibility to mechanical damage, seed longevity and tolerance to field weathering (Malik et al., 2011). Seed coat is one of the main determinants of seed germination, vigour and longevity potentials. The susceptibility to mechanical damage is related to lignin content of the seed coat, while seed longevity and tolerance to field weathering depends on seed coat integrity. Seeds having greater weight and thickness were less susceptible to mechanical damage and seeds with pigmented seed coats have a longer storage life, and chickpeas with dark seed coats store better than lighter-coloured varieties (Gvozdeva and Zhukova, 1971) and pale-seeded chickpeas are shorter lived than those with thicker, harder coats (Van der Maesen, 1984). Understanding the mechanisms of seed coat strength and flexibility, pectic polysaccharide binding, lectins and arabinogalactan-proteins allow breeding programmes to optimize milling performance in new cultivars (Wood et al., 2014). Seed hardness, small seed size, absence of anti-nutritional factors and presence of toxic substances affect bruchids damage to legume seeds (Southgate, 1979), and rough (wrinkled) and thick seed coat might be responsible for resistance to bruchids. The seed coat performs a vital function in protecting the seed prior to germination and allows the seed to remain dormant or withstand mechanical damage (Oomaha et al., 2010). In this study, the seed coat content of 19 accessions was lower than the control cultivar L 550 (kabuli type) and in 60 accessions higher than the control cultivar G 130 (desi type), thus the mini core collection offering wide diversity in both desi and kabuli types for utilization. The mini core accessions identified with higher seed coat content contribute to addressing some of these problems.

Mini core accessions showed significant differences for the physical dimensions of seeds. Kabuli types had greater GMD $(7.2 \mathrm{~mm})$ and seed volume $\left(384 \mathrm{~mm}^{3}\right)$ than the desi types (6.0 mm GMD and $220 \mathrm{~mm}^{3}$ volume) and intermediate types $\left(6.5 \mathrm{~mm} ; 270 \mathrm{~mm}^{3}\right)$. Among these three groups, there were considerable differences for the GMD as well as for seed volume $\left(6.0 \mathrm{~mm}\right.$ and $220 \mathrm{~mm}^{3}$ for desi; 7.2 $\mathrm{mm}$ and $384 \mathrm{~mm}^{3}$ for kabuli; and $6.5 \mathrm{~mm}$ and $270 \mathrm{~mm}^{3}$ for intermediate type). Considering the seed length, width, thickness, seed volume, GMD and surface area, the large-sized accessions were ICCs 8261, 9137, 12328, 14199, 15294, 15333, 15518, 15697 and 16796 in the mini core collection. The seed volume, GMD and surface area in 24 accessions was higher than the best control cultivar ICCV 2. These include 20 kabuli type and four desi type accessions (ICCs 1915, 6306, 12866 and 15294) offering wide diversity in seed dimensional traits for utilization in both the groups. The trade recognizes three groups in chickpea based on seed diameter in Europe and Australia: large seeded $(>9 \mathrm{~mm})$, medium seeded $(8-9 \mathrm{~mm})$ and small seeded $(7-8 \mathrm{~mm}$ ). Kabuli type chickpea seeds $>7 \mathrm{~mm}$ receive a premium of US $\$ 50$ per ton for each additional mm of diameter (Biçer, 2009) and the seed lot must contain a large proportion of such seeds to get the extra price (Barker, 2007).

Seed surface area, sphericity and seed shape aspect are important physical parameters contributing to the seed shape of chickpea. Overall, the mean sphericity was highest in kabuli types (85.7\%) followed by intermediate types (84.5\%) and desi types (79.5\%). Within each of these groups, there were vast differences in sphericity of seeds. It is important to evaluate the sphericity of the germplasm accessions especially for the pea-shaped accessions. Such accessions are of interest to breeders attempting to develop cultivars with diverse marketing needs. Nelson and Wang (1989) proposed a visual scoring system to describe a broad variation of seed shape. Among the tested accessions, 32 accessions had a sphericity $>85 \%$ and one accession (ICC 7323) with a sphericity $>90 \%$, representing a perfect pea shape. The mean seed shape aspect of the desi, kabuli and intermediate types was 71.2, 78.2 and $76.3 \%$, respectively. Sixteen accessions had a shape aspect $>80 \%$ including one accession (ICC 7323) with highest seed shape aspect $>84 \%$. Sphericity and seed shape aspect of chickpea seeds were significantly correlated $\left(r^{2}=0.958<0.01 \%\right)$. The 100 -seed weight and other physical dimensions significantly correlated with the sphericity and seed shape aspect of chickpea accessions (Sastry et al., 2014). In this study, we have identified nine accessions that had a seed sphericity and seed shape aspect higher than the best control cultivar ICCV 2 . These accessions include eight kabuli type (ICCs 6263, 7308, 8261, $9137,13187,13283,15435$ and 15518) and one intermediate type (ICC 7323). Dutta et al. (2004) reported a sphericity (74\%) and roundness (70\%) at 10.9\% moisture content in chickpea seeds. Higher sphericity of chickpea seeds allows more sliding and rolling during seed processing (Konak et al., 2002). Ghadge et al. (2008) studied the physical properties of chickpea split ('dhal') and identified the importance of sphericity and aspect ratio of the seeds in determining the shape of the splits ('dhal').

Chickpea seed bulk density and true seed density were negatively related to seed physical dimensions, the sphericity and seed shape aspect. The mean bulk density and true density of the desi, kabuli and intermediate types were $0.702,0.691$ and $0.707 \mathrm{~g} / \mathrm{cc}$; and $1.293,1.261$ and $1.293 \mathrm{~g} / \mathrm{cc}$, respectively. However, within each of the 
three groups, there were good differences among accessions for both bulk density and true density. In this study, 20 accessions had a seed bulk density and true density higher than the best control cultivars (G 130 and ICCV 10). These accessions include 16 desi type, two kabuli type (ICCs 11879 and 12492) and two intermediate type (ICCs 8350 and 10341). The lowest bulk density was observed in ICC 16903, a desi type chickpea with a 100-seed weight $14.4 \mathrm{~g}$ and a seed coat content $17.1 \%$. Two accessions, ICC 708 (desi) and ICC 12492 (kabuli) with 100-seed weights 13.8 and $16.5 \mathrm{~g}$ respectively, also had high bulk density. The intermediate type (pea-shaped) chickpeas have greater true densities compared with desi and kabuli types (Sastry et al., 2014). Bulk density reflects the way the seeds pack and is a useful parameter in determining the size of container needed for a given weight of seed (Gürsoy and Güzel, 2010) during seed packaging and storage. In this study, the seed bulk density and porosity was highest in ICC 10341, a kabuli type with a 100-seed weight $19.2 \mathrm{~g}$ and a seed coat content $6.0 \%$. The lowest porosity was in ICC 16903, a desi type with a 100-seed weight $14.4 \mathrm{~g}$ and a seed coat content $17.1 \%$. True seed density is a component of grain yield that is positively correlated with seed protein concentration and selection for increased density could provide an efficient way to improve protein concentration without affecting seed yield and since the measurement of seed density and seed weight is relatively inexpensive, hence a low-cost way to identify promising accessions (Li and Burton, 2002).

The seed hydration and swelling traits were negatively influenced by the seed coat content indicating higher swelling and hydration index for accessions with thinner seed coats. The mean hydration capacity and hydration index of the desi, kabuli and intermediate types were $0.153 \mathrm{~g} /$ seed and 1.158; $0.285 \mathrm{~g} /$ seed and 1.180; and $0.190 \mathrm{~g} / \mathrm{seed}$ and 1.127 , respectively. Kaur et al. (2005) reported that seeds with higher test weight and volume take higher cooking time and swelling capacity and hydration capacity correlated well with cooking time, springiness and hardness of soaked chickpea seeds. Sfayhi and Kharrat (2011) observed significant differences in physiochemical and cooking characteristics of chickpea cultivars and seeds with higher size have higher hydration capacity and longer cooking time. The mean swelling capacity and swelling index of the desi, kabuli and intermediate types were $0.137 \mathrm{ml} / \mathrm{seed}$ and $1.158 ; 0.255 \mathrm{ml} / \mathrm{seed}$ and 1.063 ; and $0.173 \mathrm{ml} / \mathrm{seed}$ and 1.025 , respectively. Among the mini core collection, 60 accessions had a seed hydration capacity of $>0.213 \mathrm{~g} / \mathrm{seed}$ and 40 accessions had a swelling capacity $>0.213 \mathrm{ml} / \mathrm{seed}$ (higher than the best control cultivar L 550). These accessions include 33 kabuli type, 17 desi type and two intermediate type (ICCs 8350 and 10341). However, seed hydration index and swelling index were higher in desi types. The hydration index was highest in desi type control cultivar (ICCV 10). Nine accessions had a swelling index higher than control cultivar G 130. Kabuli type chickpeas had high 100-seed weight, hydration and swelling capacity than desi types, indicating seed coat differences affecting the seed quality traits. Seed weight, seed volume, swelling index and hydration capacity are correlated with cooking time and these relationships enable large numbers of chickpea genotypes to be screened rapidly into long, medium and short cooking time types (Williams et al., 1983). Lopez and Fuentes (1990) and Badshah et al. (2003) observed relationships among water absorption and seed coat contents affecting the cooking quality. Ozer et al. (2010) emphasized the importance of physical, physiochemical and cooking properties of chickpeas in identification of chickpea landraces for developing high-quality chickpea cultivars.

Agbola et al. (2002) and Malik et al. (2011) emphasized the need to improve the physical quality characteristics and selections based on these traits for improvement of quality traits in chickpea. Singh et al. (2003) and Lokare et al. (2007) observed little influence of environment on seed physiochemical traits in chickpea. Hossain et al. (2010) observed low genotype $x$ environment interaction and high magnitude of heritability suggesting the environmental stability of the chickpea seed shape trait (roundness index). This is expected as this is a qualitative trait which show low environment influence and genotype $\times$ environment interaction. Genetic analysis of seed coat thickness indicated a monogenic inheritance, with the thin kabuli seed coat being the recessive character (Gil and Cubero, 1993). Selection for variation in the physical seed characters of chickpea would enable breeding of cultivars with the potential to attract premium prices. Besides seed dimensional traits, sphericity and seed shape aspect, seed volume showed positive association with hydration capacity and swelling capacity; density of seed is negatively associated with volume of seed and swelling index. Swelling index, volume of seed and cooking time had high heritability coupled with high genetic advance indicated that these characters are under additive genetic control and simple selection will be effective for their improvement (Singh, 2016). Seed weight was associated with all seed dimensions and contributed significantly to seed hydration capacity and swelling capacity. Among the observed traits, large variability was observed for seed weight, seed coat content, seed volume and seed swelling capacity and low variability for seed moisture content, seed length, sphericity and seed hydration index. Patanè et al. (2004) also reported a large variability among genotypes for swelling capacity and swelling index and lowest variability for seed coat and seed weight and identified genotypes having good seed weight and low seed coat incidence and calcium content, all important attributes affecting cooking quality. 


\section{Implications for conservation and utilization}

The relevance of seed physical properties of chickpea for conservation and utilization have been reported (Sastry et al., 2014). The seed moisture content (emc) is an important measure of seed quality influencing the physical parameters, seed handling procedures and storage behaviour of germplasm collections in the genebanks. Seed size, shape and density are important in seed cleaning process (separating seed from undesirable materials). Kabuli types were prone to seed coat-related injuries during processing resulting in poor quality and viability and seeds with pea shape and smooth surface were sensitive to drying necessitating alternate measures for reducing moisture content. Seed bulk density and porosity affect the resistance to airflow of seeds and are crucial in the development of aeration and drying systems. Seed size and porosity has significance with seed containers and processing seed samples for conservation, especially under vacuum storage compared with storage without vacuum. Highly porous seeds require more storage space during packing and chickpea seeds with higher porosity coupled with angular shape and rough seed coat surface demand additional specifications and care during sealing and storage. There are chances of damages to seed containers, especially the aluminium foil pouches as well as changes in storage environments in the containers for highly porous seeds.

\section{Multiple trait accessions}

The chickpea mini core collection has been evaluated extensively for various agronomic traits and resistance to biotic and abiotic stresses (Upadhyaya et al., 2013). In this study, top 10 accessions pooled from each seed trait resulted in 67 unique accessions (online Supplementary Table S1). Twenty-seven of these accessions were also identified as promising for important agronomic traits and resistant/tolerant to biotic and abiotic stresses during large-scale evaluations besides being genetically diverse (Upadhyaya et al., 2013). Identification of sources for different traits and utilizing them for recombinant breeding is crucial for developing chickpea cultivars to meet the emerging challenges to agricultural production (Upadhyaya et al., 2013). Accessions with desirable seed traits and as promising sources for morphoagronomic, and for biotic and abiotic stresses are presented in online Supplementary Table S2.

From this study and earlier studies, the following accessions are most promising in the chickpea mini core collection:

- ICC 637 - a desi type, tolerant to drought, salinity and heat, and agronomically superior.
- ICC 7323 - an intermediate type with best seed shape aspect and tolerant to drought.

- ICC 9137 - a kabuli type, large seeded with superior physical and hydrological seed traits including high sucrose and high ciceritol density and high yielding under high-temperature conditions.

- ICC 12328 - a kabuli type with superior physical and hydrological seed traits including high sucrose density, resistant to dry root-rot and Botrytis grey mold and agronomically superior.

- ICC 11879 - a kabuli type, high-yielding, Ascochyta blight tolerant, semi-erect, well adapted and released as cultivar in eight countries (Algeria, France, Iraq, Jordan, Lebanon, Morocco, Syria and Turkey).

- ICC 13219 - a desi type, resistant to Fusarium wilt, Botrytis grey mold and legume pod borer.

- ICC 13816 - a kabuli type, resistant to Fusarium wilt, Ascochyta blight and Botrytis grey mold, semi-erect, long duration, with high seed protein and micronutrient dense (Fe and $\mathrm{Zn}$ ), well adapted and released as cultivar in six countries (Algeria, Cyprus, Jordan, Iraq, Italy and Tunisia).

- ICC 15518 - a kabuli type with superior physical and hydrological seed traits and agronomically superior.

- ICC 15606 - a desi type with high seed density, resistant to Fusarium wilt, Botrytis grey mold and legume pod borer.

New cultivars are accepted as valuable raw material for the production of foodstuffs based on evaluation of their physical, chemical and nutritive properties. The physical traits of chickpea seeds are easy to measure and provide a base for screening and classifying large germplasm collections for utilization in research. Further studies are needed on seed traits associated with storage pests, 'dhal' recovery, cooking quality and other related consumer preferences.

The chickpea mini core collection is a global public good and representative seed samples are available for utilization in research following a Standard Material Transfer Agreement (SMTA) under the International Treaty on Plant Genetic Resources for Food and Agriculture (ITPGRFA).

\section{Supplementary material}

The supplementary material for this article can be found at https://doi.org/10.1017/S1479262119000030

\section{References}

Abbo S, Berger J and Turner NC (2003) Evolution of cultivated chickpea: four bottlenecks limit diversity and constrain adaptation. Functional Plant Biology 30: 1081-1087. doi:10.1071/FP03084. 
Agbola FW, Kelley TG, Bent MJ and Rao PP (2002) Eliciting and valuing market preferences with traditional food crops: the case of chickpea in India. International Food Agribusiness Management Review 5: 7-21.

Badshah A, Khan M, Bibi N, Khan M, Saijad A, Chaudry MA and Khattak SM (2003) Quality studies of newly evolved chickpea cultivars. Advances in Food Sciences 25: 95-99.

Barker B (2007) Grow bigger kabuli chickpea seed. Available at http://www.topcropmanager.com/content/view/1047/132/ (verified 29 Sept. 2010).

Biçer TB (2009) The effect of seed size on yield and yield components of chickpea and lentil. African Journal of Biotechnology 8: $1482-1487$.

Dua RP, Chaturvedi SK and Sewak S (2001) Reference Varieties of Chickpea for IPR Regime. Kanpur, India: Indian Institute of Pulse Research, p. 34.

Dutta SK, Nema K and Bhardwaj RK (2004) Physical properties of gram. Journal of Agricultural Engineering Research 39: 259-268.

Eissa AHA, Mohamed MA, Moustafa $\mathrm{H}$ and Alghannam ARO (2010) Moisture dependent physical and mechanical properties of chickpea seeds. International Journal of Agricultural and Biological Engineering 3: 70-83.

El-Swaify SA, Pathak P, Rego TJ and Singh S (1985) Soil management for optimized productivity under rainfed conditions in the semi-arid tropics. Advances Soil Science 1: 1-64. doi: 10.1007/978-1-4612-5046-3_1.

FAOSTAT (2016) Source: http://faostat.fao.org/ (accessed on 4 May, 2018)

Genebank Database (2018) Source: http://genebank.icrisat.org/ Characterization/frmChickpea?Crop=Chickpea .

Ghadge PN, Vairagar PR and Prasad K (2008) Physical properties of chick pea split (Cicer arietinum L.). Agricultural Engineering International: the CIGR Journal X: 1-9.

Gil J and Cubero JI (1993) Inheritance of seed coat thickness in chickpea (Cicer arietinum L.) and its evolutionary implications. Plant Breeding 111: 257-260. https://doi.org/10.1111/ j.1439-0523.1993.tb00639.x.

Gowda CLL, Upadhyaya HD, Dronavalli N and Singh S (2011) Identification of large-seeded high-yielding stable kabuli chickpea germplasm lines for use in crop improvement. Crop Science 51: 198-209.

Gürsoy S and Güzel E (2010) Determination of physical properties of some agricultural grains. Research Journal of Applied Sciences, Engineering and Technology 2: 492-498.

Gvozdeva ZV and Zhukova NV (1971) Influence of storage conditions on longevity of seeds of bean, chickpea and soybean. Trudy po Prikladnoi Botanike 45: 161-168.

Hossain S, Ford R, McNeil D, Pittock C and Panozzo JF (2010) Development of a selection tool for seed shape and QTL analysis of seed shape with other morphological traits for selective breeding in chickpea (Cicer arietinum L.). Australian Journal of Crop Science 4: 278-288.

IBPGR, ICRISAT and ICARDA (1993) Descriptors for Chickpea (Cicer arietinum L.). Rome, Italy; International Board for Plant Genetic Resources, International Crops Research Institute for the Semi-Arid Tropics, Patancheru, India and International Center for Agricultural Research in the Dry Areas, Aleppo, Syria.

ICRISAT (1994) Plant Material Description no. 57. Patancheru, Andhra Pradesh, India: International Crops Research Institute for the Semi-Arid Tropics.
ICRISAT (2009) ICRISAT Archival Report 2009. Patancheru, Andhra Pradesh, India: International Crops Research Institute for the Semi-Arid Tropics. Available at http://intranet/ddg/ Admin\%20Pages2009/Archival_Report_2009.aspx (accessed 20 March 2013).

ISTA (1993) International rules for seed testing. Seed Science and Technology 21(Suppl,): 1-288.

Jha NS (1999) Physical and hygroscopic properties of makhana. Journal of Agricultural Engineering Research 72: 145-150.

Jukanti AK, Gaur PM, Gowda CLL and Chibar RN (2012) Nutritional quality and health benefits of chickpea (Cicer arietinum l.). British Journal of Nutrition 108 (Suppl 1): S11S26. doi: 10.1017/S0007114512000797.

Kashiwagi J, Krishnamurthy L, Upadhyaya HD, Krishna HS, Chandra S and Vadez V (2005) Genetic variability of drought-avoidance root traits in the mini core germplasm collection of chickpea (Cicer arietinum L.). Euphytica 146: 213-222. doi: 10.1007/s10681-005-9007-1.

Kaur M, Singh N and Sodhi NS (2005) Physicochemical, cooking, textural and roasting characteristics of chickpea (Cicer arietinum L.) cultivars. Journal of Food Engineering 69: 511517. https://doi.org/10.1016/j.jfoodeng.2004.09.002.

Khattak AB, Khattak GSS, Mahmood Z, Bibi N and Ihsanullah I (2006) Study of selected quality and agronomic characteristics and their interrelationship in Kabuli-type chickpea genotypes (Cicer arietinum L.). International Journal of Food Science \& Technology 41(Supple. 2): 1-5.

Konak M, Carman K and Aydin C (2002) Physical properties chickpea seeds. Biosystems Engineering 82: 73-78.

Kumar J, Haware MP and Smithson JB (1985) Registration of four short duration fusarium wilt resistant kabuli (garbanzo) chickpea germplasm. Crop Science 25: 576-577. doi: 10.2135/cropsci1985.0011183X00250003004.

Li H and Burton JW (2002) Selecting increased seed density to increase indirectly soybean seed protein concentration. Crop Science 42: 393-398.

Lokare YA, Patil JV and Chavan UD (2007) Genetic analysis of yield and quality traits in kabuli chickpea. Journal of Food Legumes 2: 147-149.

Lopez BL and Fuentes M (1990) Cooking quality of chickpea. Options Méditerranéennes - Série Séminaires - n.o. 9: 113-125.

Malik SR, Saleem M, Iqbal U, Zahid MA, Bakhsh A and Iqbal SM (2011) Genetic analysis of physiochemical traits in chickpea (Cicer arietinum) seeds. International Journal of Agriculture and Biology 13: 1033-1036.

Meena HP, Kumar J, Upadhyaya HD, Bharadwaj C, Chauhan SK, Verma AK and Rizvi AH (2010) Chickpea mini core germplasm collection as rich sources of diversity for crop improvement. Journal of SAT Agricultural Research 8: 1-5.

Mehla IS, Waldia SR and Dahiya SS (2001) Variation and relationship among cooking quality attributes across the environments in 'Kabuli' chickpea (Cicer arietinum L.).Journal of Food Science and Technology 3: 283-286.

Mohsenin NN (1986) Physical Properties of Plant and Animal Materials, 2nd edn. New York: Gordon and Breach Science Publishers.

Nelson RL and Wang P (1989) Variation and evaluation of seed shape in soy bean. Crop Science 29: 147-150.

Nikobin M, Mirdavardoost F, Kashaninejad M and Soltani A (2009) Moisture-dependent physical properties of chickpea seeds. Journal of Food Processing Engineering 32: 544-564.

Omobuwajo OT, Akande AE and Sann AL (1999) Selected physical, mechanical and aerodynamic properties of African 
Breadfruit (Treculia africana) seeds. Journal of Food Engineering 40: 241-244.

Oomaha BD, Warda S and Parthiba Balasubramanian B (2010) Dehulling and selected physical characteristics of Canadian dry bean (Phaseolus vulgaris L.) cultivars. Food Research International 43: 1410-1415.

Ozer S, Karakoy T, Toklu F, Baloch FS, Kilian B and Ozkan H (2010) Nutritional and physicochemical variation in Turkish kabuli chickpea (Cicer arietinum L.) landraces. Euphytica 175: 237-249.

Pande S, Kishore GK, Upadhyaya HD and Rao JN (2006) Identification of sources of multiple disease resistance in mini core collection of chickpea. Plant Disease 90: 1214-1218. doi: 10.1094/PD-90-1214.

Patanè C (2006) Variation and relationship among some nutritional traits in Sicilian genotypes of chickpea (Cicer arietinum L.). Journal of Food Quality 29: 282-293.

Patanè C, Iacoponi E and Raccuia SA (2004) Physico-chemical characteristics, water absorption, soaking and cooking properties of some Sicilian populations of chickpea (Cicer arietinum L.). International Journal Food Science Nutrition 55: 547-554. doi: 10.1080/09637480400015836.

Ramasamy R and Harte JB (2009) Milling and physicochemical properties of chickpea (Cicer arietinum L.) varieties. Journal of the Science of Food and Agriculture 89: 258-266. https:// doi.org/10.1002/jsfa.3435.

Regan K, MacLeod B and Siddique K (2006) Production Packages for Kabuli Chickpea in Western Australia. Farm Note No. 117. South Perth, WA: Department of Agri \& Food.

Sastry DVSSR, Upadhyaya HD and Gowda CLL (2014) Determination of physical properties of chickpea seeds and their relevance in germplasm collections. Indian Journal of Plant Genetic Resources 27: 1-9.

Sfayhi D and Kharrat M (2011) Physiological and cooking characteristics of Tunisian chickpea varieties. Food 5: 68-72.

Singh T (2016) Estimation of genetic parameters and character associations for yield and quality traits in chickpea. Indian Journal of Agricultural Research 50: 117-121. doi: 10.18805 /ijare.v0iOF.8437.

Singh U, Kumar J, Jambunathan R and Smithson JB (1980) Variability in the seed coat content of desi and kabuli chickpea cultivars. International Chickpea Newsletter 3: 18.

Singh OP, Yadava HS and Agrawal SC (2003) Divergence analysis for quality traits in chickpea. Indian Journal of Pulses Research 1: 12-13.

Southgate BJ (1979) Biology of Bruchidae. Annual Review of Entomology 24: 449-473.

Sreenarayanaa VV, Visvanathan R and Subramaniyan V (1988) Physical and thermal properties of soybean. Journal of Agricultural Engineering 25: 76-82.
Tizazu H and Emire SA (2010) Chemical composition, physicochemical and functional properties of lupin seeds grown in Ethiopia. African Journal of Food, Agriculture, Nutrition and Development 10: 3029-3046.

Upadhyaya HD and Ortiz R (2001) A mini core collection for capturing diversity and promoting utilization of chickpea genetic resources in crop improvement. Theoretical and Applied Genetics 102: 1292-1298.

Upadhyaya HD, Bramel PJ and Singh S (2001) Development of a chickpea core set using geographic distribution and quantitative traits. Crop Science 41: 206-210.

Upadhyaya HD, Yadav D, Dronavalli N, Gowda CLL and Singh S (2010) Mini core germplasm collections for infusing genetic diversity in plant breeding programs. Electronic Journal of Plant Breeding 1: 1294-1309.

Upadhyaya HD, Dronavalli N, Dwivedi SL, Kashiwagi J, Krishnamurthy L, Pande S, Sharma HC, Vadez V, Singh S, Varshney RK and Gowda CLL (2013) Mini core collection as a resource to identify new sources of variation. Crop Science 53: 2506-2517. doi: 10.2135/cropsci2013.04.0259.

Vadez V, Krishnamurthy L, Serraj R, Gaur PM, Upadhyaya HD and Hoisington DA (2007) Large variation in salinity tolerance in chickpea is explained by differences in sensitivity at the reproductive stage. Field Crops Research 104: 123-129. doi: 10.1016/j.fcr.2007.05.014.

Van der Maesen LJG (1984) Seed storage, viability and rejuvenation. In: Witcombe JR and Erskine W (eds) Genetic Resources and Their Exploitation: Chickpeas, Faba Beans and Lentils. The Hague: Nyhoff-Junk, pp. 13-22.

Wang N and Daun J (2005) Determination of cooking times of pulses sing an automated Mattson cooker apparatus. Journal of the Science of Food and Agriculture 85: 1631-1635. doi: $10.1002 /$ jsfa.2134.

Williams PC, Nakoul H and Singh KB (1983) Relationship between cooking time and some physical characteristics in chickpeas (Cicer arietinum L.). Journal of the Science of Food and Agriculture 34: 492-496. doi: 10.1002/jsfa.2740340510.

Wood JA, Knights EJ and Choct M (2011) Morphology of chickpea seeds (Cicer arietinum L.): comparison of desi and kabuli types. International Journal of Plant Sciences 172: 632-643. doi: $10.1086 / 659456$.

Wood JA, Knights EJ, Campbell GM and Choct M (2014) Differences between easy- and difficult-to-mill chickpea (Cicer arietinum L.) genotypes. Part III: free sugar and non-starch polysaccharide composition. Journal of the Science of Food and Agriculture 94: 1454-1462. doi: 10.1002/jsfa.6445.

Yadav SP and Sharma SP (2000) Variation for hilum colour and its stability during four crop seasons in soybean (Glycine max L.). Indian Journal of Agricultural Sciences 71: $23-26$. 